\title{
Investor Protection and Capital Expenditures under Endogenous Time Inconsistency
}

\author{
Richard P. Gregory ${ }^{1}$ \\ ${ }^{1}$ College of Business and Technology, East Tennessee State University, Johnson City, Tennessee, USA. \\ Correspondence: Richard P. Gregory, College of Business and Technology, East Tennessee State University, Johnson \\ City, Tennessee, 37614 USA. Tel: 1-423-439-8649. E-mail: gregoryr@etsu.edu
}

Received: February 8, 2019

Accepted: March 11, 2019

Online Published: March 12, 2019

doi:10.5430/afr.v8n2p43

URL: https://doi.org/10.5430/afr.v8n2p43

\begin{abstract}
Underinvestment in value-enhancing projects is considered a major problem in corporate management. It is usually blamed on information asymmetry and agency costs. In this paper, a model is proposed that shows that even without information asymmetry and agency costs, there is a pronounced tendency for managers to underinvest due to a positive probability of their being replaced. It is also shown that investor protection legislation, if it does not eliminate the possibility of being replaced, does not lower the likelihood of underinvestment.
\end{abstract}

Keywords: capital budgeting, underinvestment, time inconsistency

\section{Introduction}

\subsection{The Problem}

It is generally assumed in the literature on capital budgeting decisions that underinvestment by firms is due to information asymmetry between management and investors or due to agency costs. The proposed solutions to this problem is often legal or regulatory. This problem is important in that as a result of such underinvestment, firms may increasingly seek to provide more dividends than is socially optimal. It is also important in that the firm, through underinvestment, is not providing value to shareholders and employment to potential employees.

Unlike previous models in the literature on capital budgeting decisions, the model proposed here, has no information asymmetry. It shows that as long as there is a positive probability of management being replaced and management owns a fraction of the firm's equity, there is always an underinvestment problem, even with no agency costs. The problem is that the potential of replacement means that management will not share in the benefits of long-term investment as fully as it would if it were still in charge. Further, the model points out that legal and regulatory requirements to protect investors from underinvestment will exacerbate firm underinvestment if the legal and regulatory requirements increase the probability of management being replaced.

The reason is that the probability of replacement changes the behavior of management, making it more myopic and procrastinating in its investment behavior. Technically, the probability of replacement forces managers to adopt time inconsistent discounting behaviors, where they value the present cash flows far higher than they ought to, given the firm's weighted average cost of capital. The result is underinvestment. The motivation for present-biased behavior in the model herein is that management teams have finite lives, and therefore may be less interested in implementing projects if they will not be in charge so as to reap the full benefits of controlling the firm when the project starts paying off. This would be particularly observed in situations where the firm is subject to an increase in regulatory scrutiny. Lel and Miller (2008) document that cross listing firms that list under more stringent regulations are more likely to see management turnover than comparable firms that do not increase the level of regulatory scrutiny they come under

That individuals can procrastinate in taking actions that generate lasting benefits to themselves and others is a phenomenon that is well-documented both in observation and in the literature on decision-making. Akerloff (1991) and O’Donoghue and Rabin (1999) explain this behavior as being due to the existence of present-biased preferences, which manifest time-inconsistent behaviors. Such individuals can put-off "net present value" investments forever, though it may be to the detriment of their own long-term interests.

Similarly, managers have been observed to delay implementing projects that could bring long-lasting benefits to themselves, shareholders and customers, if they incur immediate costs. Hiring new employees to service a growing 
customer base is often put-off by retailers and service firms, due in part to the direct and indirect costs of training new employees, which can often prove to be a multi-year investment of the firm's immediate time and resources. Further, present biased behavior has been associated with more present consumption, more risk-seeking behavior and greater used of high-interest debt (Meier and Sprenger (2010)).

It isn't surprising that if start-up costs are large, that the net benefit of a project may be negative and hence the project would not be implemented. However, in this paper it is shown that even if the net benefit for all parties is positive, a management team may procrastinate about implementing a project if they can be replaced. Each team places more weight upon the benefits they can derive from the project if they are in charge. It is shown that in such a system, the manager in any period will be faced with a present-biased, generalized hyperbolic utility function, so his behavior is constrained in a time-inconsistent manner. Amador (2004) and Furusawa and Lai (2005) show similar results for political parties.

\subsection{Underinvestment in the Literature}

The topic of corporate underinvestment has a long history in the business literature. However, the literature has long relied on the idea of information asymmetry and agency costs to explain underinvestment. Demetz (1983) argued that because managers have preferences for certain projects over others, they take this enjoyment into account in ranking projects. In Miller and Rock (1985), managers know the current state of firm earnings, but not investors. Managers thus use dividend policy as a signal about earnings to investors, even if this means investing less. Narayanan (1985) presents a model where the information asymmetry is about the quality of the manager. In this, the result is that manager boosts short-term profits over long-term investment to signal that they are a high-quality manager. Roll (1986) hypothesized that managers can overestimate their ability to manage certain projects and as a result overinvest in these projects to the exclusion of more profitable projects. Shleifer and Vishny (1989) find that management has an incentive to invest in projects that increase their bargaining power, resulting in rents that accrue to management. In Stein (1989), investors are assumed to value firms on expected future earnings and future earnings are positively correlated with present earnings. Management, aware of this thinking by investors, cut present investment to boost current earnings. Palley (1997) presents a theoretical work, based on information asymmetry, that has the key feature that if manager's rewards are based on current profitability, then rational managers may choose projects with lower net present values because the prospect of turnover means they won't be around to enjoy the returns generated by long-term projects. Asker et al $(2011,2015)$ and Davies et al (2014) find that short-termism significantly affects corporate investment, with Davies et al estimating that the level of output is $20 \%$ lower than it would be without short-term thinking.

\section{The Setup of the Model}

The model follows from similar models by Amador (2004) and Furusawa and Lai (2005). There are two managerial coalitions or groups that seek to manage the firm. One of them is currently in control of the firm in period $t \equiv\{0,1,2\}$. Let each period be a term of some length at which the managerial team is evaluated. The team that is in office is assumed to make decisions and implement policies that it prefers. It is assumed that the two possible managerial teams have the same preferences over the same decisions and policies when faced with similar circumstances. Both teams have preference that are characterized by geometric discounting and both teams have the same discount factor, $\delta$, on future payoffs, as do shareholders as a class.

It is assumed that the selection of the team in control is characterized by a Markov process, so that the current team in charge will be re-selected with probability $p \in\{0,1\}$. If $p>1 / 2$, then the current management team has a greater probability of retaining control in the next term, which means they have an incumbency advantage. It is assumed that the probability of a party being reselected is dependent upon two thing: the amount of control they have over the existing equity through ownership $(k)$ and the degree of investor protection offered either by the firm's management, $q$ or the amount of investor protection imposed by the government of the country that the firm is legally governed by, $i$.

Management in control of the firm seeks to maximize the total cash flows net of the cost of extracting private benefits and of the dividend paid to other shareholders:

$$
S_{t}=a K^{\delta}-n(K-W)-m q^{2}-0.5 b f^{2} a K^{\delta}(i+q)-(K-W)
$$

where $a K^{\delta}$ is the return on capital; $W$ is the equity management controls; $f$ is the portion of cash flows of the firm that management expropriates, $m q^{2}$ is the cost of firm level governance; and $b$ is a positive constant or function that increases with the firm's investor protection and cash flows. The degree of insider or management controlled ownership is $k=W / K . n$ is the proportional cost of raising new capital. 
Equation (1) assumes that the participation constraint of the minority shareholders is binding. The management team currently in charge maximizes (1) by choosing $f$ and $q$. In maximizing (1), it is assumed that the management team in power will only invest if $S$ is positive and that $f$ and $q$ have to be consistent with the maximization of the management team in power's welfare at the time they are chosen.

Given this, the formula that the management team maximizes with respect to $f$ will be:

$$
k(1-f) a K^{\delta}-0.5 b f^{2} a K^{\delta}(i+q)+f a K^{\delta}
$$

The utility of management over the future is expected to be :

$$
U_{t}=\sum_{j=0}^{\infty} \beta_{j} S_{t+j}
$$

where $U_{t}$ exhibits hyperbolic discounting if $\beta j_{+1} / \beta j$ weakly increases with $\mathrm{j}$.

Let $p_{j}$ denote the probability that the current management team will be in control of the firm $\mathrm{j}$ periods in the future. Let $p$ be the probability that the current management team will be in control in the next period and (1-p) be the probability that a new team will take control of the firm in the next period.

$p$ is assumed to take the form of the following function:

$$
p_{t}=(k)^{(i+q)}
$$

that is $p$ is determined by the portion of cash flows that is received by shareholders subject to the level of investor protection. $k$ is the proportion of the firm's cash flows controlled by management from its ownership, where $k=W / K$. Since the current management team is in control in the next period with probability $p$ and an opposition team will be in control with probability $(1-p) \mathrm{m}$ the value of $p_{j}$ evolves according to :

$$
p_{j+1}=1-p+(2 p-1) p_{j}
$$

setting $p_{0}=1$, the solution to this difference equation explicitly when $p \neq 1 / 2$ obtains as

$$
p_{j}=\frac{(2 p-1)^{j}+1}{2}
$$

When $p=1 / 2, p_{0}=1$ and $p_{j}=1 / 2$ for $j \geq 1$. If $p>1 / 2$, then the current management has an advantage in future periods of retaining control of the firm in that the probability of its being retained is higher in all future periods than alternatives. However, this advantage diminishes as time goes by, as can be seen in equation (5) as $p_{j}$ falls as $j$ increases. If $p<1 / 2$, then $p_{j}$ falls if $j$ is odd, while it rises if $j$ is even, with a limit of $p_{j} \rightarrow 1 / 2$ as $j$ goes to infinity. If $p=1 / 2, p_{j}=1 / 2$, ceteris paribus.

If the management team is out of office, they gain a proportion, $\alpha$, of the benefits $S$, due to severance packages and stock holdings. Observe that $u_{t+j}$ is independent of which management is in office in period $t+j$. This is because it is assumed that both management teams have the same preferences when in office and are expected to behave the same way when facing similar circumstances. So the expected one-shot payoff to management team $t$ in period $t+j$ is

$$
p_{j} u_{t+j}+\left(1-p_{j}\right) \alpha u_{t+j}=\left[\alpha+(1-\alpha) p_{j}\right] u_{t+j}
$$

the first term on the left hand side is the expected benefits accruing to the management team in office in period $t+j$.

Therefore the present discounted benefit to the management team in power at time $t$ is given by:

$$
\beta_{j}=\delta_{j}\left[\alpha+(1-\alpha) \frac{(2 p-1)^{j}+1}{2}\right]
$$

is the discount applied to the benefits to shareholders as a class $j$ periods from $t$. Note that if $\alpha=1$, the discount function reduces to the usual geometric discount function. If a management team knows that that its rivals would behave exactly as it would, the management team would behave as it would always be in office, then no present bias would obtain. Alternatively, it may be the case that shifts in the makeup of the underlying coalitions may be such that the management team in power will make up a substantial portion of any new team taking power. Henceforth, it is assumed that $\alpha<1$ unless stated otherwise.

The payoff function represented by equations (2), (5) and (7) will exhibit generalized hyperbolic discounting if $\beta_{j+1} / \beta_{\mathrm{j}}$ weakly increases with $j$. It follows from (5) and (7) that if $p \neq 1 / 2$, then 


$$
\frac{\beta_{j+1}}{\beta_{j}}=\delta\left[\frac{1+\alpha+(1-\alpha)\left(2(k)^{(i+q)}-1\right)^{j+1}}{1+\alpha+(1-\alpha)\left(2(k)^{(i+q)}-1\right)^{j}}\right]
$$

It is easily verified in (9) that if $k^{i+q}>1 / 2$, then the left hand side increases with $j$ and converges to $\delta$ as $j$ grows infinitely large. In this case, management exhibits generalized hyperbolic discounting. If $k^{i+q}<1 / 2$, then $\beta_{\mathrm{j}+1} / \beta_{\mathrm{j}}$ fluctuates around $\delta$, being less than $\delta$ when $k^{i+q}$ is even, and being greater when odd. It also converges to $\delta$ as $j$ tends towards infinity.

If $k^{i+q}=1 / 2$, then following from (9) above, it is easily verified that $\beta_{1} / \beta_{0}=\delta(1+\alpha) / 2$ which is less than $\delta$ and that $\beta_{\mathrm{j}+1} / \beta_{\mathrm{j}}$ $=\delta$ for all other $j>1$. Therefore, management will exhibit the quasihyperbolic discounting noted in Laibson (1997). The current management team will always have a $50 \%$ chance of being replaced in the next period, and will discount future benefits in the next period more heavily than the discounting from the discount factor.

Additionally, for all cases, $\beta_{\mathrm{j}+1} / \beta_{\mathrm{j}}$ takes on its smallest value when $j=0$, implying that the discount rate will always be the greatest in the current period, leading to present biased preferences.

So that it is clear that whether management exhibits present discounting depends upon $\alpha, f$, $i$ and $q$. The management team itself picks $f$ and $q$. $\alpha$ is assumed to be a function both of the management's ownership of the firm, the level of investor protection, and a constant $\gamma$ :

$$
\alpha=(k / \gamma)^{(i+q)}
$$

The constant $\gamma$ represents the flexibility of the underlying coalitions that make up the management team and the majority of the shareholders. The greater the value of $\gamma$, the less flexible the coalitions in the sense that in case of replacement, there is less compensation for the management thrown out of control of the firm.

Therefore, given (1) and (6) above, the in-place management seeks to maximize the following each period:

$$
\begin{aligned}
u_{j}=p_{j} k\left[(1-f) a K^{\delta}-0.5 b f^{2} a K^{\delta}(i+q)+f a K^{\delta}\right]+\left(1-p_{j}\right) \alpha k\left[(1-f) a K^{\delta}-\right. \\
\left.0.5 b f^{2} a K^{\delta}(i+q)\right]
\end{aligned}
$$

Maximizing with respect to $f$ :

$$
f_{j}^{*}=\frac{(1-\alpha) p_{j}(1-k) a K^{\delta}-\alpha\left(1-p_{j}\right) a K^{\delta_{k}}}{(1-\alpha) p_{j} b a K^{\delta}(i+q)-\alpha\left(1-p_{j}\right) b a K^{\delta}(i+q)}
$$

Equations (8) and (12) make clear the tradeoff facing investors in lobbying for greater investor protection from management. On the one hand, increasing investor protection lowers the percentage of moneys expropriated by firm insiders. On the other, increased investor protection increases the likelihood for management to be replaced, particularly if they are minority shareholders. In that case, the tendency towards present biasedness and time inconsistency towards new projects is more pronounced.

After determining the level of expropriation, the management team in power next determines the level of private investor protection $q$, they will provide to minority shareholders. This is determined by maximizing equation (1) with respect to $q$ so that optimal $q$ will be:

$$
q=\frac{-0.5 h \rho^{22} \alpha K^{\delta}}{2 m}
$$

where $f^{*}$ is the optimal level of expropriation as determined above. As $q$ is a product of $m$, unlike in Doidge, Karolyi and Stulz (2007), perfect markets are not assumed, and thus $m>0$. This also means that the use of government regulation in the economy imposes a real cost to the firm's management.

\section{Simulations}

Equations (12) and (13) are dependent upon on each other, so to illustrate their possible effects of regulation on present biasedness, equations (1-13) are simulated by using a series of assumed values and iteratively solving first for $f$ and then for $q$. The base case assumes the following values for the given parameters: 


\begin{tabular}{ll}
\hline Parameter & Assumed Base Value \\
\hline $\mathrm{i}$ & 3 \\
$\gamma$ & 5 \\
$\mathrm{a}$ & 0.1 \\
$\delta$ & 3 \\
$\mathrm{~K}$ & 10 \\
$\mathrm{~b}$ & 1 \\
$\mathrm{~m}$ & 0.1 \\
\hline
\end{tabular}

The solid line in Figure 1 illustrates the degree of present biasedness for each level of insider ownership. The degree of present biasedness is here defined as $\beta_{3} / \beta_{1}$. There is an inverse relationship between the level of insider ownership and the degree of present biasedness in this case. As the degree of ownership controlled by the management team in power increases, the degree of present biasedness decreases.

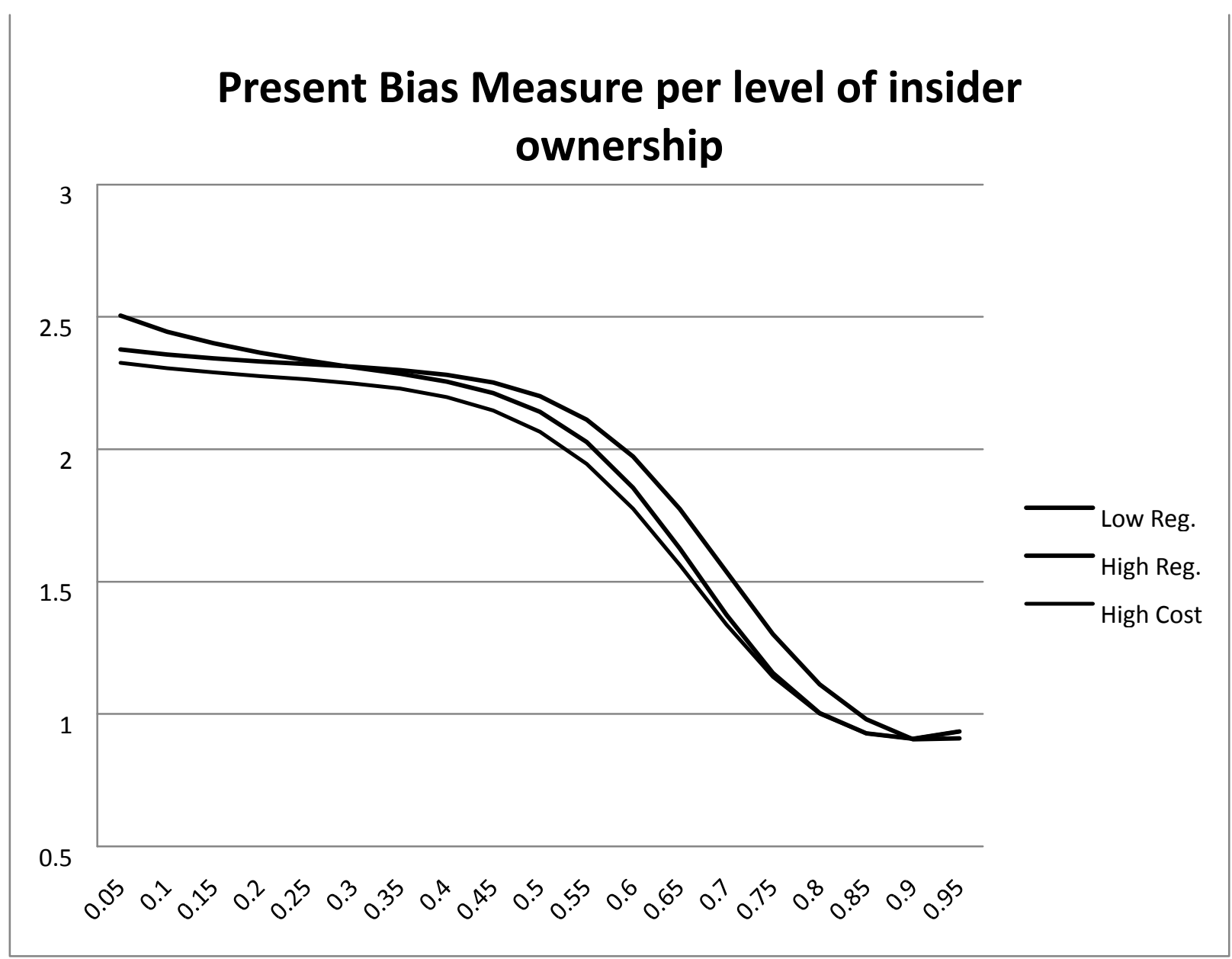




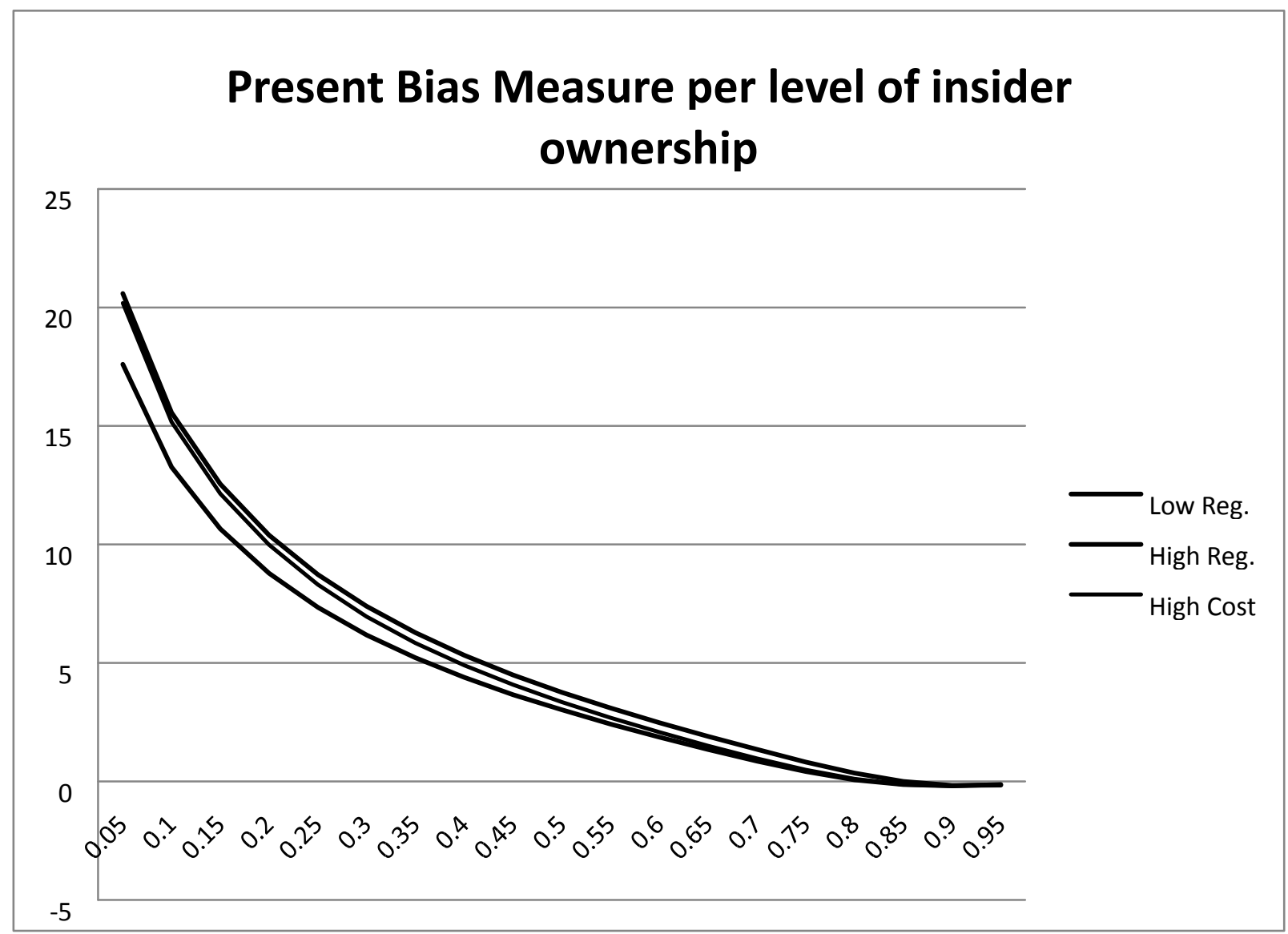

Figure 1.

Figure 1 also illustrates two other cases: First, the High Reg. case, where the level of government protection, $i$, is raised from 3 to 4; and second, the high cost of diversion case (High Cost), where $b$ is raised from 1 to 1.3 (but $i$ is left at the base value of 3). Compared to the base case, the increase in government regulation raises the degree of present biasedness for firms, except at the extremes of insider ownership. Firms with very low levels of insider ownership by the management team in power, can see less present-biasedness with higher government regulation. Firms that are almost entirely owned by the management in charge can also see a decrease in the degree of present biasedness.

The second case, where the cost of divergence goes up, results in a decline in present biasedness for all levels of insider ownership. Thus in terms of limiting present biasedness, raising the cost of divergence is much more effective than increasing the regulatory scope of oversight. Of course, it might be expected that if government regulation increases then the cost of divergence on a per unit basis might go up also. In this case, the effects of increased government regulation would be ambiguous except at the extremes, where increased government regulation would unambiguously decrease the degree of present biasedness for firms where the managing coalition owns relative little of the firm.

Figure 2 illustrates the effects of decreasing the level of flexibility in the composition of the competing coalitions. The solid line is the base case as above, while the dotted line is the level of present biasedness when $\gamma=2$, thus meaning a higher degree of flexibility. A higher degree of flexibility amongst the coalitions increases the level of present biased behavior for all levels of insider ownership, except at the highest levels.

Both figures illustrate the importance of simulation. The results of any of these single parameter variations is not straight forward due to the non-linear nature of the model. Increased government regulation that does not alter the per unit cost of compliance can increase present biased behavior for firms, unless they have relatively low levels or high levels of insider ownership. 


\section{Project Implementation}

\subsection{General Propositions}

In this section the capital budgeting decision of the firm is analyzed. O'Donoghue and Rabin (1999) amongst many others, have shown that an individual with a quasi-hyperbolic payoff function exhibits time-inconsistent behavior, including procrastination on costly projects that are expected to generate a future stream of large benefits. In the current model, the management team in control of the firm has a present-biased payoff function. All investment is funded internally. The question of external funding under present biased behavior is left to further research.

The current management team would be loath to engage in a costly project for two possible reasons: 1) at lower levels of insider ownership, the implementation of a costly project will limit the amount of cash flow that can be expropriated, and 2) at all levels of insider ownership, a project with large upfront costs and huge future benefits will not be of benefit to the current management team, unless they feel that they will still be in charge once the benefits start accruing.

However, procrastination does not have to happen even with hyperbolic discounting and even if it does, management may undertake expensive projects if they can implement them partially over time. That is, if the upfront cost is small enough, management will undertake the project immediately, if the project is of some intermediate size, they may seek to undertake the project piecemeal, though if the project cost is too high, then it may never be taken on.

Let the history $\left\{h_{l}\right\}_{l=0}^{t-1}$ of management team $t$ with the payoff function given in (10) above, and let the management team of have the choice of $h_{t}$ under the constraint that $h_{t} \geq 0$ and

$\sum_{l=0}^{t} h_{l} \leq 1$. Thus, the actions of the management team affects the decisions and payoffs of future governments and their expectations about future actions affect their decisions in the present.

Let the present discounted value of the projects net benefits in period $t$, if evaluated in period 0 , be $B=\sum_{m=0}^{\infty} \beta_{t+m}-\beta_{t} c$, where $c$ is the upfront cost of the project. Now, equation (11) above is rewritten as of period 0 for the management team in charge. The project has a normalized payoff of $\$ 1$.'

$$
U_{0}=\sum_{t=0}^{\infty} h_{t} B_{t}
$$

Where $h_{t}$ can be viewed as the fraction of a project undertaken in period $t$. As (14) is linear with respect to $\left\{\mathrm{h}_{\mathrm{t}}\right\}$, it is always in the interest of the management team in place to carry out the project when it's present value is the highest. Define $t^{*}$ as that time where the prese nt value of the project is greatest.

To find $t^{*}$, compare the values of the expected payoffs from two consecutive periods. Then the management team in power will weakly prefer having the project undertaken in period $t$ to undertaking the project in period $t+1$ if

$$
B_{t} \geq B_{t+1}
$$

or upon substituting using the definition of $B$

$$
\frac{\beta_{t+1}}{\beta_{t}} \geq \frac{c-1}{c}
$$

or, upon substitution from (9) above,

$$
\delta\left[\frac{1+\alpha+(1-\alpha)\left(2(k)^{(i+q)}-1\right)^{t+1}}{1+\alpha+(1-\alpha)\left(2(k)^{(i+q)}-1\right)^{t}}\right] \geq \frac{c-1}{c}
$$

While not easy to interpret, (17) says that unless the net discounted benefits accruing to management in period $t$, net of costs, outweighs the net benefit of delaying the project, then the project will not be taken up in the current period. Or if the net benefits to management are greater in the next period compared to the net benefits in the current period, then the management team will procrastinate.

Proposition 1. If the management team receives the same compensation out-of-power as it does when in power, there is no gain from procrastination:

Proof. Let $\alpha=1$ in equation (17). In this case the left hand side of the equation will be $\delta \geq c-1 / c$.

This will always be true as $\mathrm{c}$ is constrained between 0 and 1 and $\delta$ is by definition a positive percentage.

Proposition 2. If management owns none of the firm's equity, i.e. $k=0$, then as long as $\alpha \geq 0$, then management gains no benefits from procrastination.

Proof, again substitute into (17) above and be definition of $\mathrm{c}$ and $\delta, \delta[1+\alpha / 1+\alpha] \geq 1$-c/c always holds. 
Proposition 3. If the management team in place owns $100 \%$ of the firm $(\mathrm{k}=1)$, then there will be no tendency to procrastinate.

Proof, again, substitute and similar to Proposition 2.

So in the extremes, when management has no or total control over the ownership of the firm, there is no tendency to procrastinate on valuable projects.

However, casual substitution of values between the two extremes for $k$ quickly demonstrates that present biased behavior is possible for the intermediate values.

Corollary. For firms with no or total management control of equity, investor protection has no effect over the investment decisions of the firm

This follows from Proposition $2 \& 3$ straightforwardly. If there is no present biased behavior, investor protection, whether low or high, has any effect $\mathrm{n}$ the firm's investment decisions.

Proposition 4: If $\mathrm{c}$ is small enough, then there will always be implementation of the project at any level of insider ownership, for a given level of investor protection that is high enough.

Proof: This follows straightforwardly from (17), as long as $\mathrm{k}>0$ and $\mathrm{i}+\mathrm{q}>1$.

Proposition 5: For a high enough implementation cost, there will be no implementation of the project at any level of ownership

Proof: Again, follows from (17)

Proposition 6: The level of insider expropriation (agency costs) has no effect on firm underinvestment.

Proof: Follows from examination of the decision equation, Equation (17)

\subsection{Implementation Costs}

Now, define $\beta^{*}=\sum_{k=0}^{\infty} \beta_{k}-1 / \sum_{k=0}^{\infty} \beta_{k}$, then it follows that $\delta>\beta^{*}$, as if this weren't the case,

then $\beta^{*}>(\mathrm{c}-1 / \mathrm{c})>\delta$ which jointly implies that the project has a negative NPV and the management team finds the project worthwhile to implement in period 0 , which is nonsensical. Secondly, it follows that $\beta^{*}>\beta_{1}$ for similar reasons. Thus it is the case that $\delta>\beta^{*}>\beta_{1}$. Next, examine three possible cases:

1. $\delta>\beta^{*}>\beta_{1}>(\mathrm{c}-1) / \mathrm{c}$ (Low implementation cost projects)

2. $\delta>\beta^{*}>(\mathrm{c}-1) / \mathrm{c}>\beta_{1}$ (Intermediate Implementation cost projects)

3. $\delta>(\mathrm{c}-1) / \mathrm{c}>\beta^{*}>\beta_{1}$ (High Implementation cost projects)

\subsection{Low Implementation Cost Projects}

First consider the case where the implementation costs of the project are small such that $\delta>\beta^{*}>\beta_{1}>(\mathrm{c}-1) / \mathrm{c}$. In this case, regardless of the level of present biasedness, it always in preferable for the management team in control to implement the project using internal funding. As the cost is low compared to the benefit from implementing the project in the present, there are no benefits to management to putting off the project or implementing it in stages over time. In this case, at all levels of ownership, $\beta_{1}>(\mathrm{c}-1) / \mathrm{c}$, so it is always in the interests of the management in control to implement the project, at least by the next period in the future, if not immediately.

\subsection{Intermediate Implementation Cost Projects}

The next case is where the cost of the project is in an intermediate range such that : $\delta>\beta^{*}>(\mathrm{c}-1) / \mathrm{c}>\beta_{1}$. As Figure 2 illustrates, management teams that own a large share of the firm are unlikely to implement the project, whereas firms with managements that own less of the firm are more likely. The reasoning is as follows, management teams s with less inside control are thus gaining less benefit from assets in place, but relatively more from diverting free-cash-flow, the best way to increase free cash flow from their perspective is to take on new projects. 


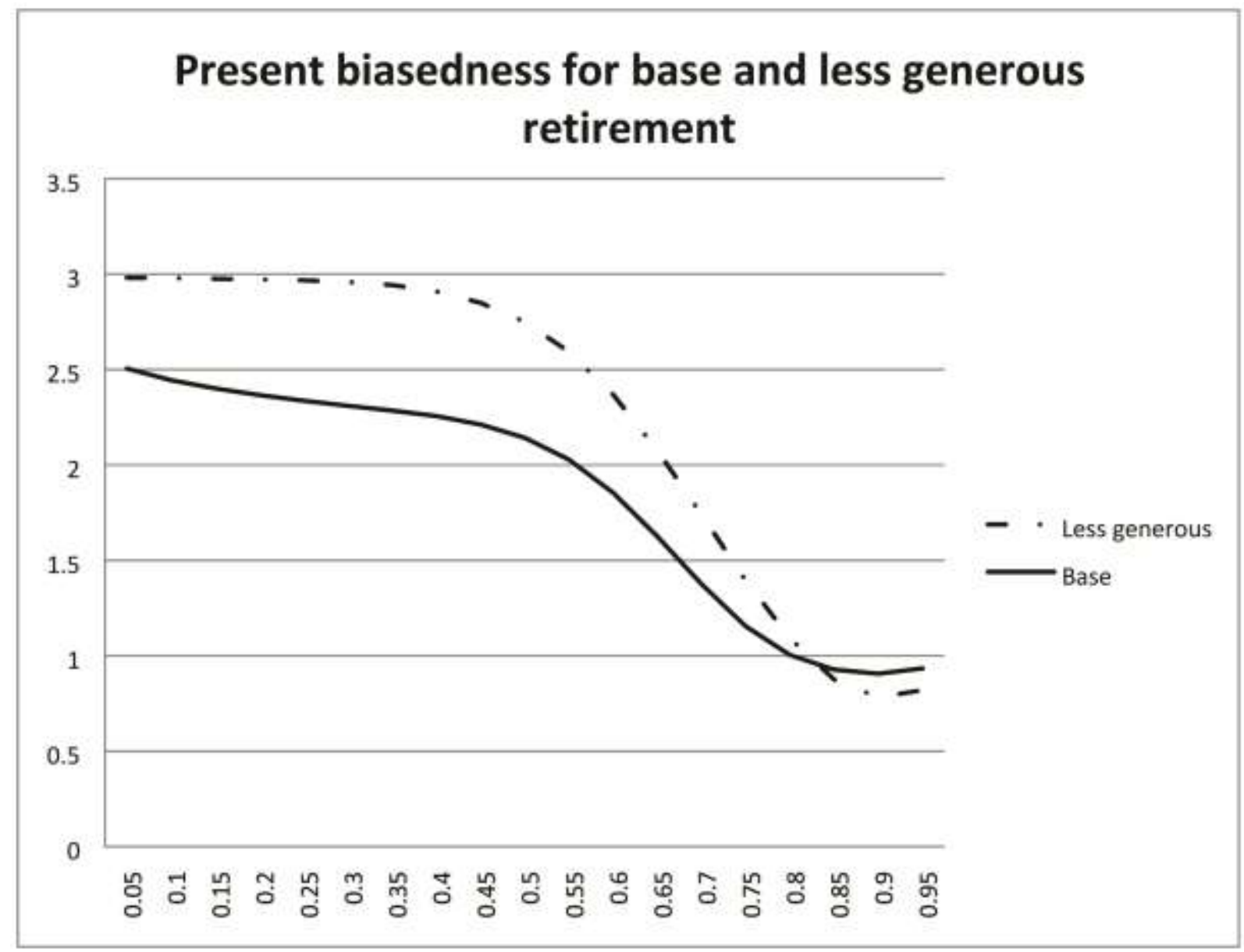

Figure 2.

The effect of raising oversight on management is interesting. Raising oversight can increase the likelihood of implementation, all things being equal, for firms where the controlling management does not own the majority of the firm. Why does increased investor protection increase the likelihood of project implementation for a given level of insider ownership?

Raising investor protection now raises the bar for management, it increases the likelihood of their replacement. In such a case, they are less able to divert internal cash flows, so as to keep up the same level of investment they need new sources of cash flows. Thus there is an incentive for less secure management teams to be disposed towards implementing new projects when scrutiny and investor protection is increased.

Figure 3 illustrates the value of $B_{1}$ under various levels of insider ownership again for the three cases: Base, High Reg. (higher regulation) and High Cost (Higher cost of diversion). Figure 3 shows that while management teams with lower control over the firms have more present biasedness, they are in this scenario more likely to implement the project, while it is management teams with more control who are less likely. 


\section{Net Benefit of Project under Intermediate cost, $c=5(B-(c-1) / c)$ for levels of insider ownership}

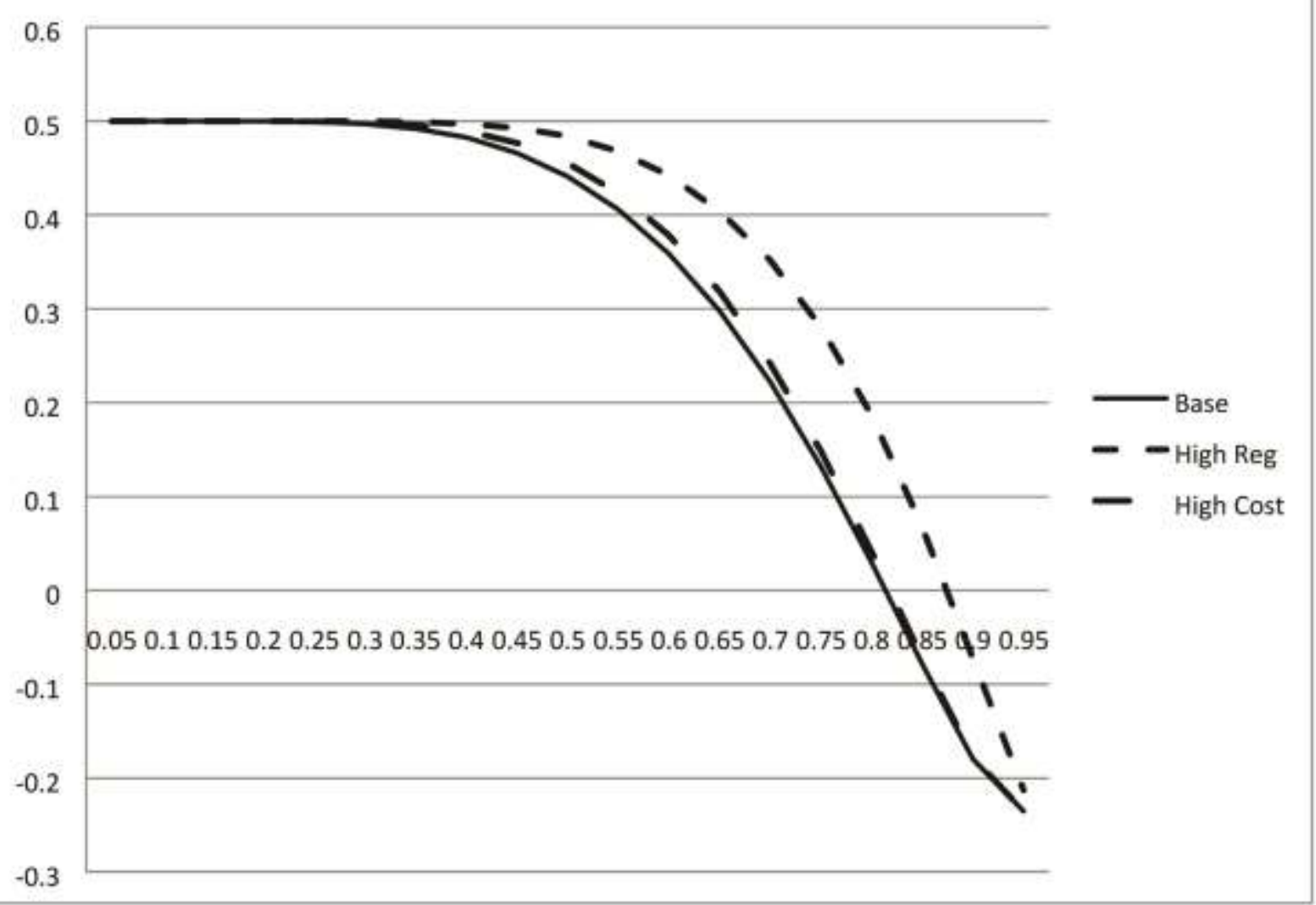

Figure 3.

\subsection{High Implementation Costs}

Lastly, consider the case where $\delta>(\mathrm{c}-1) / \mathrm{c}>\beta^{*}>\beta_{1}$. In this case, the upfront costs are high enough that from the perspective of the in place management, there is not incentive in ever implementing the project, even though it has a positive net present value for shareholders as a class. See Figure 4 . Nevertheless, every management might wish to undertake the project, as sometime in the future, $\beta_{\mathrm{t}}$ could be positive if $t$ is large enough. There is the possibility that if the project costs are divisible over time, then management will implement the project by spreading the costs over time. This is left to future research. 


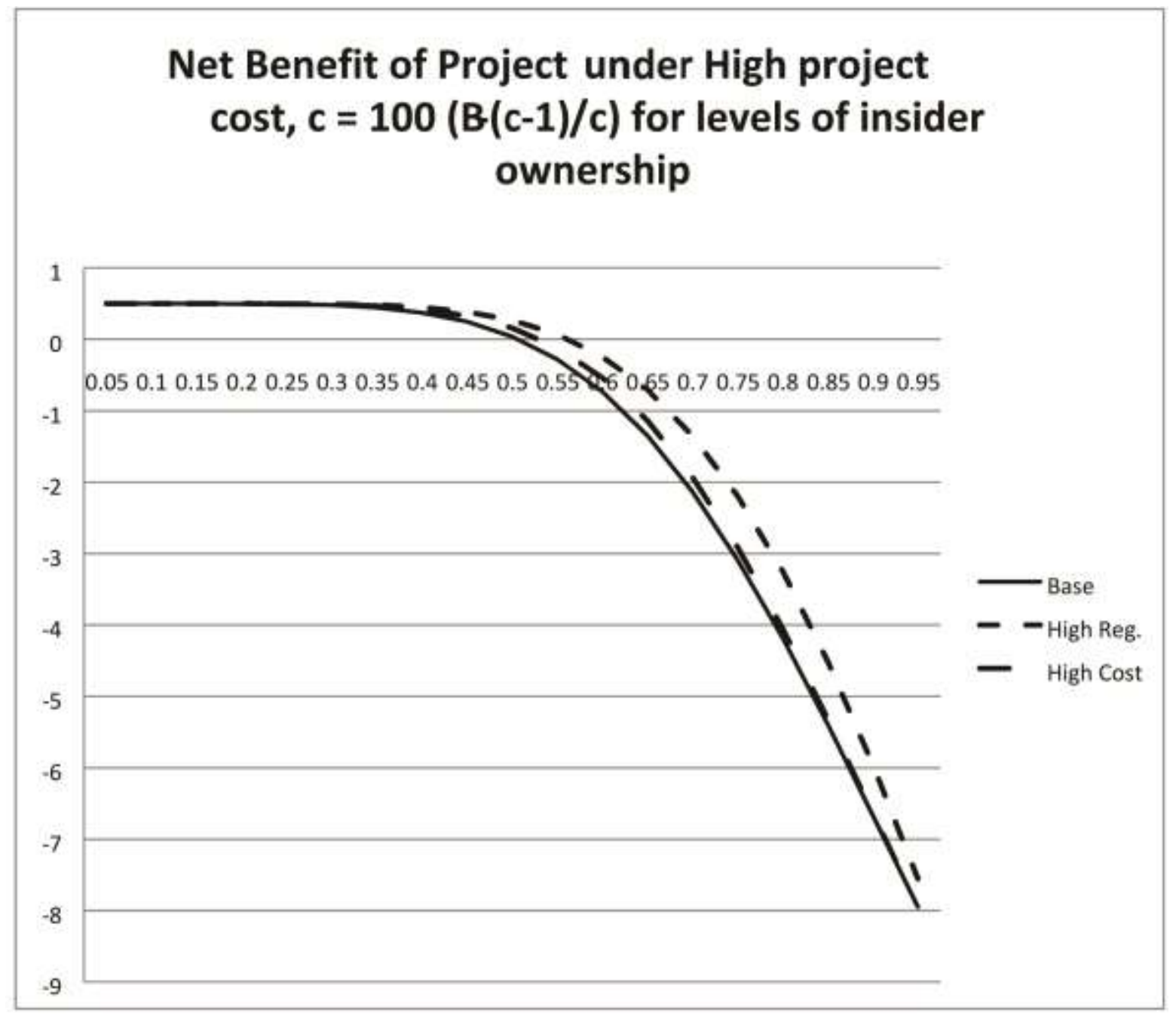

Figure 4.

\subsection{International Corporate Governance}

It has recently been recognized that the quality of corporate governance practices is positively related to growth opportunities, concentration of ownership, need for external financing and the protection of investor rights (See Durnev and Kim (2005), Klapper and Love (2003) and Krishnamurti, Sevic and Sevic (2005)).Doidge, Karolyi and Stulz (2007) develop a model of corporate governance without allowing for present biasedness and find that increased firm specific corporate governance increases the value of the firm.

The major difference in the present model is that increased investor protection will yield benefits only for some firms. Firms that are young, with little internal cash flow to expropriate with management team not owning a large part of the firm are more likely to benefit as the higher regulatory environment will decease expropriation while also possibly increasing the degree of present biasedness in the firm. Since these firms typically would be expected to derive most of their asset value from growth opportunities, the effects on project implementation may be such that major projects, from which the firm derives the majority of its value, will still be implemented, in that they are riskier. The major impact that present-biased ness would have is that lower risk projects, though necessary in the long run, would be pushed aside or implemented slowly. Further, there would be an increased tendency to use risky debt on the part of such firms to enhance the available cash flow.

Most of the tests in the literature tests the valuation effects from cross-listing firms. The prediction of the current model is ambiguous. On the one hand, the cross listing will lower the cost of capital and the degree of expropriation of minority shareholders, but this may be meaningless in the long run. While it will tend to curb expropriation of minority shareholders in the long run the firm will exhibit more present biased behavior and under invest in sure projects, seek out riskier projects and be more inclined to issue risky debt. The result is that there is little in the way of long term value 
gains for the firm. This prediction correlates with the recent empirical evidence reported by Sarkissian and Schill (2009), who find little evidence for a permanent effect on stockholder returns for firms that list abroad, even when controlling for liquidity, legal protection and access to a larger shareholder base. In terms of the present model, this result is explained by that though greater legal protection does decrease shareholder expropriation, the increased likelihood of managerial turnover increases the present biasedness of the firm's management, making them more likely to increasing risky behavior while taking on more debt, while at the same time rejecting otherwise profitable projects because of their delay in benefits.

Therefore, one way of viewing the differences in the prediction of the present model versus the legal bonding hypothesis of Coffee (1999) and Stulz (1999) is that in our model there is a tradeoff in the firm legally bonding itself to stronger legal and regulatory standards. While the higher legal and regulatory environment decreases the expropriation of cash flow by the firm's management, it also increases the likelihood of their being replaced. Therefore firms will seek to cross-list when they feel that the likely benefits of lower capital costs and liquidity in the foreign market outweigh the potential loss of control from the increased scrutiny from the higher regulatory environment. An increase in the foreign regulatory environment will especially be heavy on less secure management, especially if they do not own a large proportion of the firm or if the firm is a growing firm that does not have a lot of assets in place, as their value is mostly from future projects, where the increased present-biasedness from higher regulation is more likely to make them turn down projects that are not risky enough and thus have lower value to potential foreign shareholders. Piotroski and Srinivasan (2008), have documented that the increased regulation in The United States securities market from the Sarbanes-Oxley Act has resulted in fewer small firms listing in the United States. They attribute this primarily to higher costs, but the results may also be due to an understanding that the cross-listing is less likely to be received as a positive event, as the firms management may be less likely to invest the proceeds wisely from the standpoint of outside shareholders.

\section{Conclusion}

Generally, it is accepted that corporate underinvestment is due to information asymmetry between corporate management and investors and/or agency costs, as corporate management expropriates resources of the firm for less valuable purposes. The model proposed here is different in that it relies on neither information asymmetry or agency costs to result in the proposition that corporate underinvestment is a rational outcome of corporate management. It finds that the only circumstance needed for corporate underinvestment is a positive probability of corporate management being replaced in the future. The higher the probability of replacement, the higher the likelihood of underinvestment.

It is often thought that legal and regulatory restrictions can overcome the underinvest5mednt problem. The results presented here casts doubt on this form of solution. It is demonstrated that if legal and regulatory restrictions raise the probability of managerial turnover, they actually exacerbate the underinvestment problem of the firm. Unless laws and regulations the make the firm less opaque also limit the effects on managerial turnover, revealing more information is likely to lead to more underinvestment.

The model is limited in that it does not include the possibility of external financing of the firm. However, given the additional; information released by the firm in order to obtain outside financing, it can be extrapolated that if such information raises the probability of managerial turnover, then it is likely that there will still be an underinvestment problem. Further exploration of his is left to future research.

Another limitation of the model is that it does not allow for the development of factions of management teams. Management teams may splinter and separate over time, affecting the probability of retention in the next period. This splintering may be affected by a number of external and internal factors. Also left out is the possibility that management can influence the probability of being retained if they increase present cash flows to investors, assuming some investors are also time inconsistent in their preferences. This is left to future research.

A final limitation of this model is in measuring its empirical implications. What is needed is a measure of the likelihood of management being replaced. This may be possible through factor analysis or through an empirical verification of the support that management has from shareholders, but currently, such data is not available. Again, this is left to future research.

\section{References}

Akerlof, G. A. (1991) Procrastination and Obedience, American Economic Review, 81(2), 1-19.

Amador, M. (2004). A Political Model Sovereign Debt Repayment, 2004 Meeting Papers 762, Society for Economic Dynamics. 
Asker, J., Farre-Mensa, J., Ljungvist, A. (2011). Comparing the investment behavior of public and private firms. NBER Working Paper 17394. https://doi.org/10.3386/w17394

Asker, J., Farre-Mensa, J., Ljungvist, A. (2015). Corporate investment and stock market listing: A puzzle? The Review of Financial Studies, 28(2), 342-390. https://doi.org/10.1093/rfs/hhu077

Coffee, J. (1999). The future as history: The prospects for global convergence in corporate governance and its implications. Northwestern University Law Review, 93, 641-707. https://doi.org/10.2139/ssrn.142833

Davies, R., Haldane, A.G., Nikelsen, M., Pezzini, S. (2014). Measuring the costs of short-termism. Journal of Financial Stability, 12, 16-25. https://doi.org/10.1016/j.jfs.2013.07.002

Demetz, H. (1983). The structure of ownership and the theory of the firm. Journal of Law and Economics, 26, 375-390. https://doi.org/10.1086/467041

Doidge, C., Karolyi, G., Stulz,R. (2007). Why do countries matter so much for corporate governance? Journal of Financial Economics, 86(1), 1-39. https://doi.org/10.1016/j.jfineco.2006.09.002

Durnev, A., Kim, E.H. (2005). To steal or not to steal: firm attributes, legal environment, and valuation. Journal of Finance, 60(3), 1461-1493. https://doi.org/10.1111/j.1540-6261.2005.00767.x

Francis, S. Karolyi, G. (2003). The effects of market segmentation and investor recognition on asset prices : evidence from foreign stock listing in the United States. Journal of Finance, 54, 981-1013.

Furusawa, T.,Lai, E. L.-C. (2006). Endogenous present biasedness and policy implementation. Working paper. https://papers.ssrn.com/sol3/papers.cfm?abstract_id=934997.

Klapper, L., Love, I. (2003). Corporate Governance, investor protection and performance in emerging markets, Journal of Corporate Finance, 10(5), 703-728. https://doi.org/10.1016/S0929-1199(03)00046-4

Krishnamurti, C. , Sevic, A., Sevic, Z. (2005). Legal environment, firm-level corporate governance and expropriation of minority shareholders in Asia. Economic Change and Restructuring, 38(1), 85-111. https://doi.org/10.1007/s10644-005-4524-4

Laibson, D. (1997). Golden eggs and hyperbolic discounting. Quarterly Journal of Economics, 112, $443-477$. https://doi.org/10.1162/003355397555253

Lel, U., Miller, D.P. (2008). International cross-listing, firm performance and top management turnover: A test of the bonding hypothesis. Journal of Finance, 63(4), 1897-1937. https://doi.org/10.1111/j.1540-6261.2008.01377.x

Meier, S., Sprenger, C. (2010). Charging Myopically Ahead: Evidence on present-biased preferences and credit card borrowing. American Economic Journal: Applied Economics, American Economic Association, 2(1), 193-210, January

Miller, M.H., Rock, K. (1985). Dividend policy under asymmetric information. The Journal of Finance, 40(4), 1031-1051. https://doi.org/10.1111/j.1540-6261.1985.tb02362.X

Narayanan, M.P. (1985). Managerial incentives for short-term results. The Journal of Finance, 40(5), $1469-1484$. https://doi.org/10.1111/j.1540-6261.1985.tb02395.x

O’Donoghue, T., Rabin, M. (1999). Doing it now or later, American Economic Review, 89, $103-124$. https://doi.org/10.1257/aer.89.1.103

Palley, T.I. (1997). Managerial turnover and the theory of short-termism. Journal of Economic Behavior \& Organization, 32, 547-557. https://doi.org/10.1016/S0167-2681(97)00012-7

Piotroski, J.D., Srinivasan, S. (2008). Regulation and Bonding: The Sarbanes-Oxley Act and the Flow of International Listings. Journal of Accounting Research, 46(2), 383-425. https://doi.org/10.1111/j.1475-679X.2008.00279.x

Roll, R. (1986). The hubris hypothesis of corporate takeovers. Journal of Business, 59, $197-216$. https://doi.org/10.1086/296325

Sarkissian, S., Schill, M.J. (2009). Are there permanent valuation gains to overseas listing? Review of Financial Studies, 22(1), 371-412. https://doi.org/10.1093/rfs/hhn003

Shleifer, A., R. Vishny. (1989). Managerial enrichment: The case of firm-specific assets. Journal of Financial Economics, 25, 123-139. https://doi.org/10.1016/0304-405X(89)90099-8

Stein, J. (1989). Efficient capital markets, inefficient firms: a model of myopic corporate behavior. Quarterly Journal of Economics, 104(4), 655-669. https://doi.org/10.2307/2937861

Stulz, R. (1999). Globalization, corporate finance, and cost of capital. Journal of Applied Corporate Finance, 12 , 8-25. https://doi.org/10.1111/j.1745-6622.1999.tb00027.x 